\title{
A Framework for Evaluating Learning Progressions on Features Related to Their Intended Uses
}

\author{
Jennifer L. Kobrin \\ Pearson, Wayne, New Jersey \\ Sarah Larson \\ CTB/McGraw Hill, San Antonio, Texas \\ Ashley Cromwell \\ Pearson, Austin, Texas \\ Patricia Garza \\ Pearson, San Antonio, Texas
}

\begin{abstract}
In recent years, learning progressions (LPs) have captured the interest of educators and policy makers. There have been numerous efforts to develop LPs aligned to college and career readiness standards, to unpack these standards, and to provide more clarity on the pathways students follow to reach them. There is great variation, however, in the structure, content, and features of LPs, and these have implications for the LP's most appropriate use. The purpose of this research was to devise a framework to understand and evaluate key features of an LP, including its structure, content, usability, and validity evidence. We maintain that educators and other stakeholders should understand these key features so they can evaluate whether an LP is appropriate for an intended use.
\end{abstract}

Keywords: learning progressions, learning trajectories, Common Core, standards, mathematics

\section{Introduction}

One of the driving forces in the U.S. education system is the establishment of rigorous college and career readiness standards. Every state has been challenged to create world-class, internationally benchmarked standards and assessments that prepare students for success in college and the workforce. The standards must be based on evidence of what students should know and be able to do to be on track for college readiness when they graduate high school. Most U.S. states have adopted the Common Core State Standards (National Governors Association Center for Best Practices, Council of Chief State School Officers, 2010), whereas some states have adopted their own college and career readiness standards. In all cases, these standards provide clear end goals for learning and achievement in each grade or course. These grade-level targets build on each other so that students will be college ready by the end of high school. The standards, however, provide less detail about how students move from target to target. This gap can be filled by learning progressions (LPs). LPs focus on how students learn and develop increasing sophistication in their domain knowledge, thus articulating the pathway and conceptual milestones that students need to reach on their way toward achieving the target standards.

Please address queries to: Jennifer L. Kobrin, Center for College and Career Success, Research and Innovation Network, Pearson, Wayne, NJ. Email: jennifer.kobrin@pearson.com 
As defined by the National Research Council (2001), LPs are "descriptions of the successively more sophisticated ways of thinking about a topic that can follow one another as children learn about and investigate a topic over a broad span of time" (pp. 165-166). The mathematics field commonly uses the term learning trajectories (LTs) to describe a similar concept, so the terms LTs and LPs will be used interchangeably throughout this paper.

According to Shavelson and Kurpius (2012), some of the essential elements of LPs include

- the notion of learning as developmental, something that happens over time;

- the importance of instruction in facilitating the movement of learners across the learning continuum as they progress from novice to more expert in their thinking and conceptual understanding; and

- empirical research and validation to both establish and continually refine the LPs.

LPs differ from standards, scope and sequence documents, and curriculum frameworks in several key ways. Whereas standards are aspirational and describe expected performance for students at particular grade and/or age levels, LPs represent hypotheses about how students' understanding develops and may not be tied to specific ages or grades. Whereas scope and sequence documents and curriculum frameworks are developed based on conventional wisdom and expert consensus on the learning process, LPs are based on empirical evidence of students' learning pathways and are subject to refinement and revision if subsequent data do not support the LP hypothesis (Corcoran, Mosher, \& Rogat, 2009). In addition, scope and sequence documents specify discrete objectives for students to achieve at each grade, but these are not connected in a clear way to provide a coherent vision of how learning develops (Heritage, 2008). LPs make these connections explicit.

In recent years, LPs have captured the interest of educators and policy makers. There have been several efforts to develop LPs in mathematics, science, and English language arts that are aligned to college and career readiness standards, which unpack these standards and provide more clarity on the pathways that students follow to reach them. Because many different LPs have been developed, a systematic way to compare and evaluate LPs for various purposes would be of value. Corcoran and colleagues (2009) called for a set of "criteria for what would be an acceptable learning progression" (p. 33). Toward that goal, this paper describes an initial approach to understand the structure, content, usability, and validity of LPs, so that educators and other stakeholders can use the framework as criteria to evaluate whether an LP is appropriate for an intended use.

\section{Different Uses of Learning Progressions}

Just as tests can be used for different purposes and require validity evidence for each intended use and interpretation, LPs also have several different potential uses that should be examined and validated. For example, LPs can be used to inform development of standards, to guide curriculum development, to build large-scale assessments, to help teachers conduct formative assessment, and to help teachers in their own professional development. Gotwals (2012) emphasized that an LP that works well for one purpose may not be easily translated or used in a different context or for a different purpose. Each potential LP use is elaborated here.

\section{Standards Development}

LPs can provide added coherence, empirical grounding, and cognitive depth to standards (Foster \& Wiser, 2012). Gotwals (2012) identified four criteria for an LP to be useful for informing standards: (a) it must cover a broad range of content and center on core ideas, which are ideas that scientists 
think are important; (b) it must have a lower anchor that takes into account students' preconceptions in a domain; (c) it must have an upper anchor that is empirically shown to be attainable by students graduating high school; and (d) it must include empirically based milestones that represent the major stages of conceptual development toward the upper anchor. To be useful for informing standards, an LP also needs to have a relatively large grain size (i.e., the amount of content in a stage or level or the size of the shift between levels) and should span multiple years or grade levels.

Mosher (2011) noted that LPs can provide evidence to the education system on what is reasonable to expect from most students, which may not only inform standards, but can also facilitate discussion of what kinds of resources and instruction are realistic to help most of them meet higher standards. However, Foster and Wiser (2012) clearly described the challenges in using LPs to inform standards, citing the standards revision process undertaken by the Massachusetts Department of Education in 2009. For example, one key challenge was establishing the upper anchor because there was tension between aspirational statements regarding what students should know at certain points in time and empirical evidence showing what students can realistically master in those timeframes.

\section{Curriculum Development}

As LPs represent hypotheses about the instruction and experiences that should effectively enable students' conceptual development, they can be used as a framework for curriculum development by helping curriculum developers understand when, and in what order and intensity, specific content and skills should be taught (Corcoran et al., 2009). In addition, student misconceptions can be linked to specific curricular activities enabling teachers to probe student understanding and address those misconceptions (Davis \& Krajcik, 2005).

In order for an LP to be useful for curriculum development (and increase the likelihood of producing effective curricula with fewer cycles of testing and refinement), a strong research base is essential (Wiser, Smith, \& Doubler, 2012). An LP also needs clearly defined levels of achievement (intermediate knowledge states), including a description of the lower anchor which represents the knowledge or naïve conceptions that students have before receiving instruction. The lower anchor is especially important because LP-based approaches to curriculum design assume "not only that students' initial ideas are meaningful but also that they are the only basis on which to build further understanding" (Wiser et al., 2012, p. 397). Many researchers agree that instruction-assisted learning is an important component of an LP (Duschl, Maeng, \& Sezen, 2011); however, not all LPs include specific instructional interventions. In most cases, a wide range of curricular sequences could be derived from a single LP. Therefore, it would be pragmatic to empirically examine different curriculum sequences to determine which are most successful in helping students move to higher levels of the LP.

\section{Large-Scale Summative Assessment}

As noted in several national assessment policy documents (e.g., National Research Council, 2006; National Assessment Governing Board, 2011), LPs can be very useful for assessment design and are being recommended for new large-scale assessment frameworks, including the National Assessment of Educational Progress and assessments based on the Next Generation Science Standards. LPs may be used to align large-scale assessments with current research on how students learn and may represent a new vision where assessments are organized around a smaller number of core concepts that show continuity across grade levels and are assessed in greater depth (Alonzo, Neidorf, \& Anderson, 2012). 
In order to inform the design of large-scale assessments, LPs should have a strong research base and a well-grounded framework. LPs that address core ideas are more likely to be consistent with largescale assessment frameworks than those addressing more discrete topics. Moreover, LPs that are linked to a specific curriculum are not appropriate for a large-scale assessment that is intended for administration to students being taught with many different local curricula.

Alonzo et al. (2012) provided other cautions in implementing an LP-based approach to large-scale assessment systems, citing key conceptual and procedural differences in item development, item analysis and evaluation, the design of operational assessments, and scoring and reporting. For example, large-scale assessment items are typically developed using pre-determined specifications. Conversely, an LP-based approach to item development requires an iterative process whereby items are developed and pilot tested, and data are used to refine both the items and the LP itself. In addition, large-scale assessments typically have broad content coverage and items are developed to adequately cover the content domain. In contrast, LP-based assessments require overrepresenting specific or discrete content areas to get adequate measurement for each achievement level on the LP.

\section{Formative Assessment and Instruction}

LPs provide great potential as the basis of formative assessment and instruction. Heritage (2008) promoted LPs for their promise in supporting and enhancing teachers' formative assessment by enabling them to focus on important learning goals and see connections between those goals. Compared to formative and interim assessments used by teachers today, assessments based on LPs could provide information that is more easily interpreted and allows teachers to make better informed and more precise decisions about student needs and appropriate instructional responses (Corcoran et al., 2009).

For an LP to be useful for teachers, it should be linked to appropriate assessment tasks that reveal students' reasoning along the progression, and it should also be linked to instructional tasks specifically designed to address students' learning needs at various locations on the LP (Battista, 2011). Classroom teachers need LPs at a relatively fine grain size in order to evaluate and respond to questions and ideas raised in classroom discussion or on assessments, but not too fine a grain size to become overwhelmed with the number of levels of achievement to understand and address.

\section{Teacher Development}

LPs have recognized potential for supporting teachers' preparation, practices, and professional growth (Furtak, Thompson, Braaten, \& Windschitl, 2012). The promise of LPs for teacher development lies in their potential for increasing teachers' pedagogical content knowledge (Shulman, 1986) and providing them with a "pedagogical vision" (Furtak et al., 2012, p. 428), that is, a progression of content and practices that can be developed over time and a deeper understanding of how students learn and develop more sophisticated understanding in a domain, which can guide their instructional decisions. To be useful for teacher development, LPs should be accompanied by tools (e.g., assessments, feedback strategies) that support and scaffold teachers' practice (Furtak et al, 2012). The grain size of the LP should allow teachers to set goals, both for themselves and for their students, and imagine the next steps in their teaching.

Given the different characteristics of LPs needed to support these multiple potential uses, the purpose of this research was to devise a framework to serve as a tool to determine whether an LP is appropriate for its intended use(s). In the sections that follow, we discuss the development of the framework and parameters and how the parameters are related to intended uses of an LP. 


\section{Framework Development}

The research team consisted of three former K-12 educators with established expertise in assessment, academic standards, mathematics, and research; and one research scientist with expertise in measurement and evaluation and familiarity with the literature on LPs. A multistep process was used to develop the framework. First, the research team reviewed the literature to identify characteristics and elements of LPs that are commonly recognized and are measurable or have measurable qualities. Based on this literature review, the team identified initial parameters for the framework, which were organized into four dimensions: structure, content, usability, and validity.

Next, the research team applied the initial framework to three sets of LPs that were aligned to or based on the Common Core State Standards in Mathematics: TurnOnCCMath.net Learning Trajectories for the K-8 Common Core Math Standards (Confrey, Nguyen, \& Maloney, 2011), Progressions for the Common Core State Standards in Mathematics (Common Core Standards Writing Team, 2013), and Learning Progressions Frameworks Designed for Use With the Common Core State Standards in Mathematics K-12 (Hess, 2010). The team met several times to discuss each LP's elements and characteristics in relationship to the framework's parameters. As a result of those discussions, the framework parameters were modified and further developed. Figure 1 displays the framework's final dimensions and parameters. The Appendix provides a full description of each parameter in the framework.

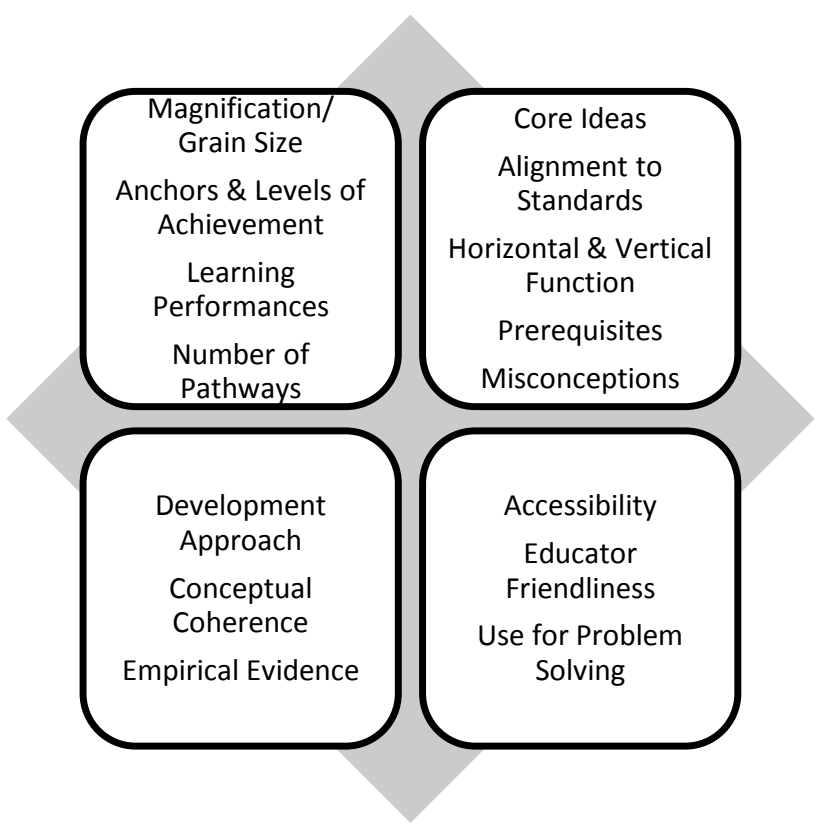

Figure 1: Learning Progression Review Framework 
Using the final framework, each research team member studied one of the selected LPs in depth and evaluated it with regard to each of the framework parameters. The entire team discussed all three LPs and reached full consensus before the results were summarized and written up. During the process of reaching consensus, the framework was further refined until it adequately captured and measured all relevant characteristics of the three LPs that were reviewed. The full reviews for each LP are available from the authors by request.

\section{How the Review Parameters Are Related to Intended Uses of Learning Progressions}

In the sections that follow, we describe each parameter in our framework and discuss how it is related to the potential uses of LPs that were described earlier. Table 1 displays a summary of the parameters which are deemed most important to consider for each potential use of an LP.

Table 1: Classification of Learning Progression Parameters and Potential Uses

\begin{tabular}{|c|c|c|c|c|c|}
\hline & Standards & Curriculum & $\begin{array}{c}\text { Large- } \\
\text { Scale } \\
\text { Assessment } \\
\end{array}$ & $\begin{array}{c}\text { Formative } \\
\text { Assessment }\end{array}$ & $\begin{array}{c}\text { Teacher } \\
\text { Development }\end{array}$ \\
\hline \multicolumn{6}{|l|}{ Structure } \\
\hline Magnification & * & * & * & * & * \\
\hline \multirow{2}{*}{$\begin{array}{l}\text { Anchors and levels of } \\
\text { achievement }\end{array}$} & $*$ & $*$ & $*$ & $*$ & * \\
\hline & & & $*$ & $*$ & * \\
\hline Learning performances & & * & & * & * \\
\hline \multicolumn{6}{|l|}{$\begin{array}{l}\text { Number of pathways } \\
\text { (multiple) }\end{array}$} \\
\hline \multicolumn{6}{|l|}{ Content } \\
\hline Core ideas & * & * & * & & \\
\hline Alignment to standards & * & * & * & & \\
\hline \multirow{2}{*}{$\begin{array}{l}\text { Horizontal and vertical } \\
\text { function }\end{array}$} & * & $*$ & * & $*$ & * \\
\hline & & * & & * & * \\
\hline \multirow{2}{*}{\multicolumn{6}{|c|}{$\begin{array}{l}\text { Prerequisites } \\
\text { Misconceptions }\end{array}$}} \\
\hline & & & & & \\
\hline \multicolumn{6}{|l|}{ Usability } \\
\hline \multirow{2}{*}{$\begin{array}{l}\text { Accessibility and } \\
\text { friendliness }\end{array}$} & & & & * & * \\
\hline & & & & * & * \\
\hline \multicolumn{6}{|l|}{ Problem-solving } \\
\hline \multicolumn{6}{|l|}{ Validity } \\
\hline Development approach & * & * & * & & \\
\hline Conceptual coherence & * & * & * & * & * \\
\hline Empirical evidence & & & & & \\
\hline
\end{tabular}

\section{Structure Parameters}

The structure parameters describe an LPs magnification or grain size, anchors and levels of achievement, learning performances, and the number of learning pathways. 


\section{Magnification or Grain Size}

The magnification or grain size of an LP defines the level at which the LP provides information about student learning and is a critical feature for any intended use. An LP that is "zoomed out" provides insights about student learning over broad periods of time, often from grade level to grade level or across multiple grade levels. These may be most useful for informing standards or large-scale assessments. LPs that are "zoomed-in" have narrower, but more in-depth, focus and provide insights about student learning over shorter periods of time, often from concept to concept or from one skill to the next. As such, finer-grained LPs are necessary for formative assessment.

An LP that offers both magnification levels would be ideal if it is intended for use in curriculum development or teacher development, as this would provide an overview about how learning develops over longer spans of time, while also providing insights about learning within smaller timeframes. Because "there is no grain size that works with all LPs, nor is there a grain size that speaks to all stakeholder groups" (Mohan \& Plummer, 2012, p. 142), an LP that offers both levels of magnification is appealing to support multiple uses.

\section{Anchors and Levels of Achievement}

The upper and lower anchors of an LP define the range of students' knowledge development by providing the starting and ending points of the progression. Levels of achievement describe the qualitatively different ways of thinking about a topic as students move from their initial naïve conceptions at the lower anchor to the highest level of sophisticated thinking at the upper anchor. Levels of achievement are commonly represented as stages, and describe students' mental models and the way that they reason about phenomena as their thinking becomes more sophisticated over time, with both maturation and instruction (Gotwals, 2012).

The presence or absence of clearly defined anchors and levels of achievement has implications for how an LP can best be used. For example, LPs that have clearly defined upper anchors can be used to inform standards, by indicating what might be realistic expectations for students. The lower anchor is important for curriculum development, formative assessment, and teacher development because it provides insight into the instructional and assessment strategies that can be used to build on students' preconceptions.

Levels of achievement are particularly important for an LP's use in standards development because they can provide empirically based milestones. In addition, achievement levels can be used in curriculum development, formative assessment, and teacher development to provide teachers with the conceptual milestones to address with students. LPs that do not have clearly defined levels of achievement can still be useful for formative assessment and teacher development, but it may be more difficult for teachers to visualize students' learning pathways and the milestones students reach along those pathways.

\section{Learning Performances}

Learning performances are descriptions of what students should be able to do at each level of achievement, and describe the activities and evidence that teachers should look for to determine where students are located on an LP. These are especially important when using an LP for assessment, as the learning performances clearly define the knowledge, skills, and abilities that should be used to design and score an assessment. LPs that provide clear learning performances may also facilitate teacher development by helping teachers better understand their students' thinking, thereby helping them determine more targeted and effective instructional strategies and become a better teacher. 


\section{Number of Pathways}

The number of pathways represented by an LP also has implications for its use. It would be challenging to use an LP with multiple pathways to inform standards or large-scale assessment because this might imply a different set of standards for each pathway. LPs with multiple pathways might be best used for curriculum development, formative assessment, and teacher development, as these provide information to help teachers better customize and personalize instruction based on a student's particular pathway.

\section{Content Parameters}

The content parameters describe whether an LP is based on core ideas, is aligned to a set of standards, functions horizontally or vertically, describes prerequisites, and includes misconceptions.

\section{Core Ideas}

LPs that address core ideas are broadly applicable to a number of topics and/or domains. Core ideas are those that experts consider important for a learner to know, and which are "unifying concepts that helps make sense of a broad variety of phenomena, situations, and problems" (Plummer, 2012, p. 78). In general, this parameter is important for any use, particularly for informing standards, curriculum development, and large-scale assessment, as LPs that are not based on core ideas are limited in their generalizability and applicability to a variety of situations and problems. However, LPs that are not based on core ideas may be useful in formative assessment and teacher development, as they can still provide insight into students' learning of specific topics, even if the learning in that topic is not widely applicable to other topics or domains.

\section{Alignment and Adherence to Standards}

Any LP used for curriculum development or large-scale assessment would need to be aligned to existing standards given schools' accountability requirements. If the primary use of an LP is for formative assessment and/or teacher development, standards alignment is not compulsory, but it is probably desired to ensure coherence and consistency with standards-based curricula and assessment.

\section{Horizontal and Vertical Functions}

LPs can describe learning within a grade level focusing on a shorter time span (horizontal), or across grade levels with a longer time span (vertical). Vertical alignment is critical for informing the creation of standards, as standards should represent not only what happens in a grade level, but also the changes in knowledge and skills that are expected between grade levels. However, if an LP is being utilized for formative assessment or for teacher development, it is more important to focus horizontally with greater depth on a single grade level over shorter time spans. Teachers will be better equipped to adjust instruction with in-depth knowledge around the progression of skills within their grade level of focus.

\section{Prerequisite Knowledge}

Some LPs may assume prerequisite knowledge that is not explicitly described in the lower anchor. It is important for an LP to clearly define prerequisites if it is to be used for curriculum development, formative assessment, and teacher development so that teachers understand their students' preconceptions in a domain. It is not necessary to clearly define prerequisites if the LP is intended to inform standards or large-scale assessment, because these uses would typically require descriptions of target achievement goals and milestones rather than detailed information about students' prerequisite knowledge. 


\section{Misconceptions}

Some LP developers believe misconceptions are an integral part of LPs because they are central to making sense of student knowledge and practice at different levels (Mohan \& Plummer, 2012) and can identify productive stepping stones in students' learning (Wiser et al., 2012). Thus, LPs that include student misconceptions may be particularly valuable for curriculum development and formative assessment. However, it may not be desirable to include misconceptions in LPs if their primary use is to guide standards development or large-scale assessment, as it may not be politically acceptable to include inaccurate ideas when LPs are used in more high-stakes contexts (Foster \& Wiser, 2012).

\section{Usability Parameters}

Usability refers to the ease and extent to which a teacher or other educator can use the LP for instruction or assessment. Two very important aspects of usability are accessibility of the LP and the extent to which it can be used for problem solving in the classroom.

\section{Accessibility and Educator Friendliness}

An LP may be considered to be accessible and friendly to educators if

- resource materials needed to understand the LP are present within the LP itself or are easily accessed through hyperlinks or common access points;

- the LP can be easily viewed or read for a horizontal time frame (within grade level) and/or vertical time frame (across grade levels);

- the LP clearly depicts the most common and/or multiple learning pathways for learners;

- the LP is not limited to a sequencing of concepts, but also includes instructional support scenarios, potential misconceptions, and concrete examples of learning processes; and

- the LP includes assessments or other tools that help a teacher use the LP in his/her classroom.

For LPs to realize their promise for improving teaching and learning, it is critically important that they are accessible and user-friendly for educators. However, this is less important if the primary use of an LP is to inform standards, curricula, or large-scale assessment.

\section{Use as Problem-Solving Tool}

Problem solving can occur at numerous levels during planning and instruction. an LP can serve as a problem-solving tool by helping teachers

- identify potential student misconceptions that occur during learning;

- determine possible concepts that may need to be retaught or reviewed;

- determine how to approach instruction on a specific concept or skill;

- reorganize curriculum or instructional plans to better accommodate students' learning pathways; and

- consider the appropriateness of instructional programs or practices for a particular age group and/or skill level.

LPs that are most useful for problem solving would likely have a relatively small grain size (i.e., zoomed-in), provide clear levels of achievement and learning performances, describe multiple pathways, focus horizontally, and include student prerequisites and misconceptions. The extent to which an LP can be used for problem solving is most important for formative assessment and teacher development, but this feature is not necessary for other uses of an LP. 


\section{Validity}

As LPs are considered hypotheses about how students' learning develops over time, evidence is needed to support the validity of those hypotheses. First, LPs should be developed based on researchbased evidence of student learning; they should have conceptual coherence, and they should be grounded in empirical data collected from real students (Anderson, 2008).

\section{Research-Based Development Approach}

The method and approach taken to develop an LP is based on certain epistemological assumptions, or a theory of how students learn. Duschl and colleagues (2011) distinguished between "evolutionary" and "validation" LP models, according to the underlying theory of conceptual change. Validation LPs are based on a misconception or "fix it" view of conceptual change (p. 156) and typically have upper anchors that represent scientifically or mathematically correct understanding. Evolutionary LPs are based on an intuition or productive misconception-based "work with it" view of conceptual change (p. 156) and have lower anchors reflecting learners' personal perspectives and views, as well as intermediate levels that used to help students "bolster meaning making and reasoning" (p. 157).

LPs can be developed using one of two different approaches. LPs developed with a top-down approach, or the "curriculum and instruction" road (Shavelson \& Kurpius, 2012, p. 17), are based on domain expert sequencing or curriculum aligned sequencing of domain topics, content, and knowledge and often result in a single or linear pathway that experts expect student learning to follow. This approach is aligned with Duschl and colleagues' (2011) validation LP perspective. Conversely, the bottom-up approach, or the "learning and cognition" road (Shavelson \& Kurpius, 2012 , p. 19) begins with a psychological analysis of the cognition underlying the content domain. It focuses on structuring and sequencing domain content based on research about how students' thinking changes as they gain increasing sophistication. The bottom-up approach, consistent with the evolutionary LP perspective, sometimes identifies multiple pathways that student's thinking may take as their sophistication increases. LPs developed using a bottom-up approach are generally supported by the research literature on how students learn in a domain, while this support may or may not be present for LPs developed using a top-down approach.

The approach taken to develop an LP is most important when it is intended to inform standards, curricula, or large-scale assessment. LPs developed purely with a bottom-up approach may not be acceptable for high-stakes uses; these uses also require expert and/or practitioner consensus that are reflected in a top-down approach. However, LPs developed using a bottom-up approach could still be very useful for formative assessment and teacher development. There is consensus in the literature that it is valuable to combine the two approaches so that an LP is informed both by research and expert knowledge (Battista, 2011; Gotwals \& Alonzo, 2012; Shavelson \& Kurpius, 2012).

\section{Conceptual Coherence}

Conceptual coherence of an LP is the extent to which the LP "makes sense" and tells a "comprehensive and reasonable story of how initially naïve students can develop mastery in a domain" (Anderson, 2008, p. 3). Conceptual coherence is necessary for any intended use of an LP, as it would be difficult to justify using an LP that does not possess this quality.

\section{Empirical Evidence}

While many LPs may have a strong research base, very few empirically validated LPs actually exist (Heritage, 2013). Anderson (2008) argued that while conceptual coherence and development from a 
strong research base are important as a first step, "the model gains both power and validity through 'ground-truthing'-the painstaking process of empirical validation" (p. 5).

Strong validity evidence for an LP is important for all intended uses, but it is not compulsory. In theory, a strong research base is what distinguishes LPs from what have been termed content progressions or scope and sequence documents. However, there is wide variability in the extent to which existing LPs are developed purely from research as opposed to expert and practitioner consensus. Although it would be ideal for an LP to have a strong research base for any type of use, in practice, one could use an LP without a strong research base, especially because there is not a sufficiently strong research base in every content area that is covered by existing standards. Until the research from the learning sciences catches up, the educational community should continue to use and test LPs and refine them using empirical data collected from students. Teaching experiments and action research conducted by collaborative teams of teachers and researchers can be pivotal in learning what works and what doesn't work and help amass both empirical evidence and practical wisdom to refine and improve LPs (Shavelson \& Kurpius, 2012).

\section{Discussion}

LPs have clear promise for informing standards, positively impacting formative assessment practices, guiding curriculum development, improving pedagogy, and enriching pedagogical content knowledge for teaching. However, it is important for LP users to understand that the value and "usability" of any particular LP will vary depending on the purpose subscribed to it. Different LPs developed for the same content domains may have markedly different features, and these differences have implications for their intended use(s). We believe that the framework and parameters developed in this study are useful for educators and other stakeholders in determining whether the features of a particular LP support its intended use(s).

The primary goal of this study was to use the extant research literature on LPs to elucidate salient features of LPs that are important with regard to their intended uses. Because LPs are still relatively new and have not been widely implemented, with increased use of LPs for various purposes, we expect that our review framework and parameters will require refinement or revision. When evaluating our framework, we focused on only three mathematics LPs that were all linked to a common set of mathematics standards; thus, there were many similarities in the features of these three LPs. We would expect a wider range in the results if the framework and parameters were used to review other mathematics LPs, as well as LPs in science and English language arts. Therefore, the framework should be substantiated and validated by application to other LPs.

As research on LPs is still in the early stages and there is not a well-developed research base documenting best practices, it is important to articulate how an LP will be used for its intended purpose(s) and what classroom and school supports are necessary to accomplish those goals. Once an LP is selected and its intended uses are designated, a theory of action or logic model should be developed to clearly specify the cause-effect relationships that will lead from the use of the LP to its intended outcomes. For example, if an LP is identified for formative assessment and instructional improvement, a theory of action should specify how the LP fits into an instructional system and is related to curriculum; is coordinated with teachers' routines and practices; and supports peer-to-peer interactions and engagement, independent learning and other critical formative processes (Confrey et al., 2010). This is sometimes referred to as instructional validity, the extent to which an LP (or assessments or teacher tools based on an LP) supports teaching practice and provides valuable and timely instructional information (Confrey, Hasse, Maloney, Nguyen, \& Varela, 2010). This clear 
specification of an LPs role in an education system will help maximize the potential for LPs to facilitate teaching and learning and move students toward the targets set by rigorous college and career readiness standards.

\section{References}

Alonzo, A. C., Neidorf, T., \& Anderson, C. W. (2012). Using learning progressions to inform largescale assessment. In A. C. Alonzo \& A. W. Gotwals (Eds.), Learning progressions in science: Current challenges and future directions (pp. 3-12). Rotterdam, The Netherlands: Sense Publishers.

Anderson, C. W. (2008). Conceptual and empirical validation of learning progressions. Retrieved from http://www.cpre.org/ccii/images/stories/ccii_pdfs/learning\%20progressions\%20anderson.pdf

Battista, M. T. (2011). Conceptualizations and issues related to learning progressions, learning trajectories, and levels of sophistication. Montana Mathematics Enthusiast, 8, 507-569.

Common Core Standards Writing Team. (2013, March 1). Progressions for the Common Core State Standards in Mathematics (draft). Tucson, AZ: Institute for Mathematics and Education, University of Arizona.

Confrey, J., Hasse, E., Maloney, A. P., Nguyen, K. H., \& Varela, S. (2010). A summary report from the conference Designing Technology-Enabled Diagnostic Assessments for K-12 Mathematics. Retrieved from http://gismo.fi.ncsu.edu/conference-report-designing-technology-\%C2\%ADenableddiagnostic-assessments-for-k-\%C2\% AD12-mathematics/

Confrey, J., Nguyen, K. H., \& Maloney, A. P. (2011). Hexagon map of Learning Trajectories for the K-8 Common Core Mathematics Standards. Retrieved from http://www.turnonccmath.net/?p=map

Corcoran, T., Mosher, F. A., \& Rogat, A. (2009). Learning progressions in science: An evidenced-based approach to reform. (Consortium for Policy Research in Education Research Report \#RR-63). New York, NY: Center on Continuous Instructional Improvement, Teachers CollegeColumbia University.

Davis, E. A., \& Krajcik, J. S. (2005). Designing educative curriculum materials to promote teacher learning. Educational Researcher, 34, 3-14.

Duschl, R., Maeng, S., \& Sezen, A. (2011). Learning progressions and teaching sequences: A review and analysis. Studies in Science Education, 47, 123-182.

Foster, J., \& Wiser, M. (2012). The potential of learning progression research to inform the design of state science standards. In A. C. Alonzo \& A. W. Gotwals (Eds.), Learning progressions in science: Current challenges and future directions (pp. 3-12). Rotterdam, The Netherlands: Sense Publishers.

Furtak, E. M., Thompson, J., Braaten, M., \& Windschitl, M. (2012). Learning progressions to support ambitious teaching practices. In A. C. Alonzo \& A. W. Gotwals (Eds.), Learning progressions in science: Current challenges and future directions (pp. 405-433). Rotterdam, The Netherlands: Sense Publishers.

Gotwals, A. W. (2012). Learning progressions for multiple purposes: Challenges in using learning progressions. In A. C. Alonzo \& A. W. Gotwals (Eds.), Learning progressions in science: Current challenges and future directions (pp. 461-472). Rotterdam, The Netherlands: Sense Publishers. 
Gotwals, A. W., \& Alonzo, A. C. (2012). Introduction: Leaping into learning progressions in science. In A. C. Alonzo \& A. W. Gotwals (Eds.), Learning progressions in science: Current challenges and future directions (pp. 3-12). Rotterdam, The Netherlands: Sense Publishers.

Heritage, M. (2008). Learning progressions: Supporting instruction and formative assessment. Paper prepared for the Formative Assessment for Teachers and Students (FAST) State Collaborative on Assessment and Student Standards (SCASS) of the Council of Chief State School Officers (CCSSO).

Heritage, M. (2013). Formative assessment in practice: A process of inquiry and action. Cambridge, MA: Harvard Education Press.

Hess, K. K. (2010). Learning progressions frameworks designed for use with the Common Core State Standards in Mathematics K-12. Dover, NH: National Alternate Assessment Center at the University of Kentucky and the National Center for the Improvement of Educational Assessment.

Mohan, L., \& Plummer, J. (2012). Exploring challenges to defining learning progressions. In A.C. Alonzo \& A.W. Gotwals (Eds.), Learning progressions in science: Current challenges and future directions (pp. 139-147). Rotterdam, The Netherlands: Sense Publishers.

Mosher, F. A. (2011). The role of learning progressions in standards-based education reform. (Policy Brief RB-52). Consortium for Policy Research in Education.

National Assessment Governing Board. (2011, September). Science framework for the 2011 National Assessment of Educational Progress. Retrieved from http://www.nagb.org//content/nagb/assets/documents/publications/frameworks/science-2011.doc

National Governors Association Center for Best Practices \& Council of Chief State School Officers. (2010). Common core state standards. Washington, DC: Authors.

National Research Council. (2001). Knowing what students know: The science and design of educational assessment (J. Pelligrino, N. Chudowsky, \& R. Glaser Eds.). Committee on the Foundations of Assessment, Board on Testing and Assessment, Center for Education. Division of Behavioral and Social Sciences and Education. Washington, DC: National Academy Press.

National Research Council. (2006). Systems for state science assessment. Washington, DC: National Academy Press.

Plummer, J. D. (2012). Challenges in defining and validating an astronomy learning progression. In A. C. Alonzo \& A. W. Gotwals (Eds.), Learning progressions in science: Current challenges and future directions (pp. 77-100). Rotterdam, The Netherlands: Sense Publishers.

Shavelson, R. J., \& Kurpius, A. (2012). Reflections on learning progressions. In A. C. Alonzo \& A. W. Gotwals (Eds.), Learning progressions in science: Current challenges and future directions (pp. 13-26). Rotterdam, The Netherlands: Sense Publishers.

Shulman, L. S. (1986). Those who understand: Knowledge growth in teaching. Educational Researcher, 15, 4-14.

Wiser, M., Smith, C. L., \& Doubler, S. (2012). Learning progressions as tools for curriculum development: Lessons from the Inquiry Project. In A. C. Alonzo \& A. W. Gotwals (Eds.), Learning progressions in science: Current challenges and future directions (pp. 359-403). Rotterdam, The Netherlands: Sense Publishers. 


\section{Appendix}

\section{Details of Learning Progression Framework Parameters}

\begin{tabular}{|c|c|}
\hline \multicolumn{2}{|r|}{ Structure } \\
\hline Magnification/ & Zoomed in: \\
\hline \multirow[t]{9}{*}{ Grain size } & $\begin{array}{l}\text { Addresses and displays content at the domain, skill subskill, and often } \\
\text { sub-subskill level }\end{array}$ \\
\hline & $\begin{array}{l}\text { Expands display or description of skills to provide examples of learning } \\
\text { experiences, misconceptions that may occur during learning, and/or } \\
\text { suggestions of how to deconstruct skills for teaching purposes. }\end{array}$ \\
\hline & $\begin{array}{l}\text { Displays or discusses how students' progression of sophistication in } \\
\text { understanding and skills happens over short periods of time; sometimes } \\
\text { even from one skill to the next. }\end{array}$ \\
\hline & $\begin{array}{l}\text { Includes the microscopic details necessary to designing curricula and } \\
\text { classroom instruction }\end{array}$ \\
\hline & $\begin{array}{l}\text { Describes or displays how progression happens horizontally through a } \\
\text { grade and vertically across grades. }\end{array}$ \\
\hline & Zoomed out: \\
\hline & Displays content at a domain, skill and rarely the sub-skill level. \\
\hline & $\begin{array}{l}\text { Describes or displays how progression happens horizontally through a } \\
\text { grade and vertically across grades. }\end{array}$ \\
\hline & $\begin{array}{l}\text { Displays or discusses how students' progression of sophistication in } \\
\text { understanding and skills happens over mid to long periods of time; from } \\
\text { domain to domain or grade to grade verses skill to skill. }\end{array}$ \\
\hline \multirow[t]{4}{*}{$\begin{array}{l}\text { Anchors and levels } \\
\text { of achievement }\end{array}$} & $\begin{array}{l}\text { Has an established upper anchor or target describing existing } \\
\text { expectations of what the student should know and be able to do once achievement } \\
\text { of learning progression (LP) has occurred (Corcoran et al., 2009). }\end{array}$ \\
\hline & $\begin{array}{l}\text { Has an established a lower anchor at beginning of the progression that } \\
\text { describes entry assumptions of what the student knows or should be able } \\
\text { to do before entering the progression (Corcoran et al., 2009). }\end{array}$ \\
\hline & $\begin{array}{l}\text { Has established intermediate, coherent sets of ideas to use as learning } \\
\text { targets for specific grade levels. }\end{array}$ \\
\hline & $\begin{array}{l}\text { Has established detailed ideas or skills that require reconceptualization and } \\
\text { promote movement from one intermediate idea to the next and can drive } \\
\text { the design of activities. }\end{array}$ \\
\hline $\begin{array}{l}\text { Learning } \\
\text { performances }\end{array}$ & $\begin{array}{l}\text { Has learning performances that describe specific practices characteristic of } \\
\text { students who are at particular levels of achievement. }\end{array}$ \\
\hline $\begin{array}{c}\text { Number of } \\
\text { pathways }\end{array}$ & Displays or discusses multiple potential pathways of learning. \\
\hline \multicolumn{2}{|r|}{ Content } \\
\hline \multirow[t]{2}{*}{ Core ideas } & $\begin{array}{l}\text { The underlying concepts of the LP are identified as important for a learner } \\
\text { to know, understand, and synthesize by experts and/or expert } \\
\text { organizations within the content area. }\end{array}$ \\
\hline & $\begin{array}{l}\text { The underlying concepts of the LP are unifying concepts that explain a } \\
\text { variety of phenomena and are learned/applied in a variety of contexts. }\end{array}$ \\
\hline \multirow[t]{2}{*}{$\begin{array}{l}\text { Alignment to } \\
\text { standards }\end{array}$} & $\begin{array}{l}\text { The content is based upon or significantly relatable to a broadly accepted set } \\
\text { of content standards. }\end{array}$ \\
\hline & $\begin{array}{l}\text { The clarification or representation of the LP is articulated by representing a } \\
\text { broad or narrow segment of an accepted set (acceptance defined by the } \\
\text { entity utilizing the LP) of content standards. }\end{array}$ \\
\hline
\end{tabular}




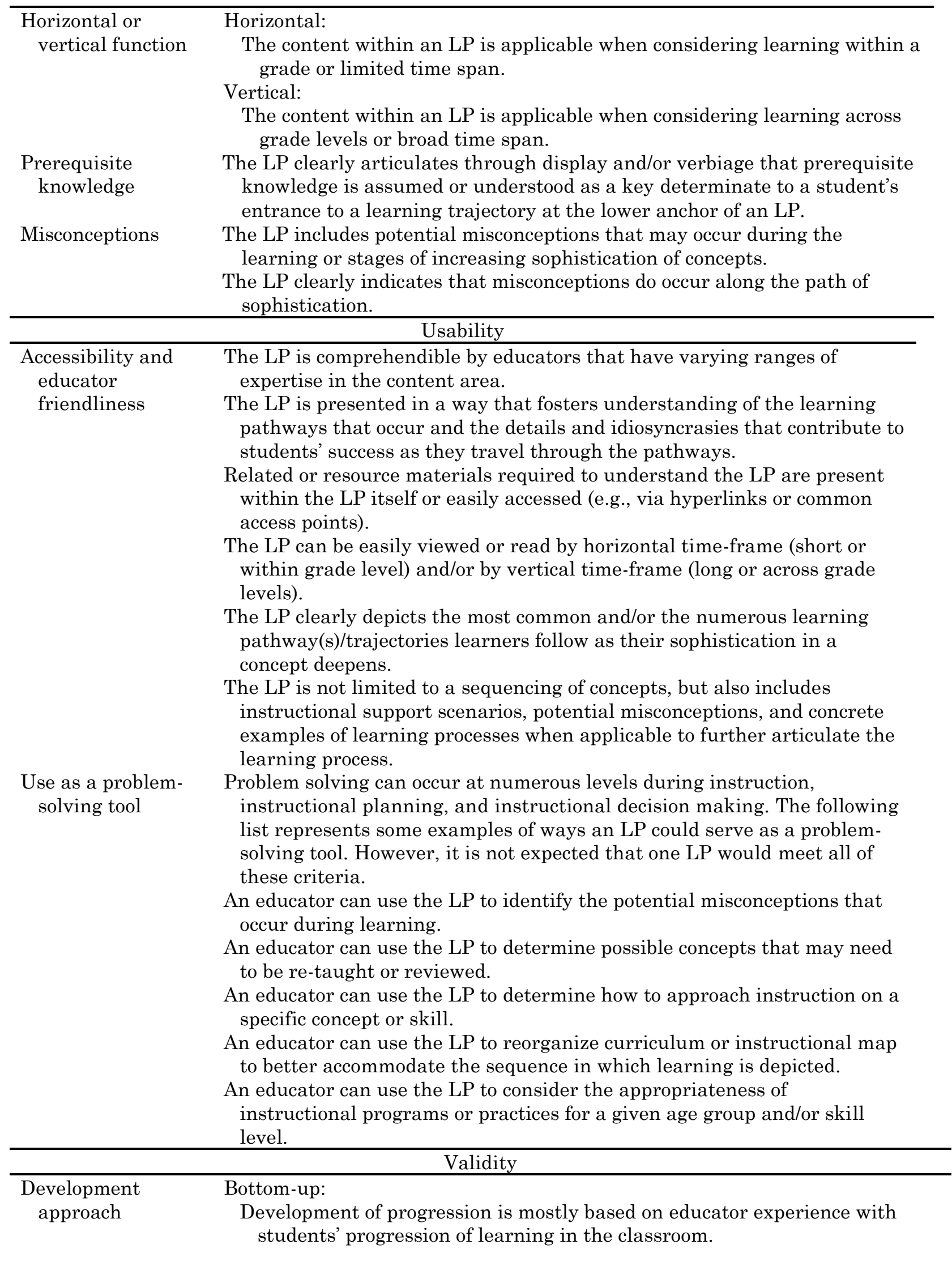




\begin{tabular}{ll}
\hline & Top-Down: \\
& Development of progression is mostly based on a logical task analysis of \\
& content domains by academic domain experts based on learning theory \\
& research.
\end{tabular}

The Journal of Educational Research and Practice provides a forum for studies and dialogue that allows readers to better develop social change in the field of education and learning. Journal content may focus on educational issues of all ages and in all settings. It also presents peer-reviewed commentaries, book reviews, interviews of prominent individuals, and additional content. The objectives: We publish research and related content that examines current relevant educational issues and processes aimed at presenting readers with knowledge and showing how that knowledge can be used to impact social change in educational or learning environments. Additional content provides an opportunity for scholarly and professional dialogue regarding that content's usefulness in expanding the body of scholarly knowledge and increasing readers' effectiveness as educators. The journal also focuses on facilitating the activities of both researcher-practitioners and practitioner-researchers, providing optimal opportunities for interdisciplinary and collaborative thought through blogging and other communications.

Walden University Publishing: http://www.publishing.waldenu.edu 